\title{
Fatigue strength assessment of bridge dilatation shutter in real operation
}

\author{
Miroslav Šulko ${ }^{1, *}$ and Matúš Margetin ${ }^{1}$ \\ ${ }^{1}$ Slovak University of Technology, Faculty of Mechanical Engineering, Department of Applied \\ Mechanics and Mechatronics, Námestie slobody 17, 81231 Bratislava, Slovakia
}

\begin{abstract}
In general, the bridge dilatation shutters and their components are dynamically loaded structures and so, the fatigue strength for such bridge joints should be analytically evaluated during design process. Due to difficulties arisen in calculation of acting forces on individual components the bridge shutters were assessed in a real operation. In the article, there will be presented results and diagrams obtained from direct measurements of the time depending strain i.e. stress processes in the critical points for that bridge dilatation joint. In addition, the results obtained from measurements and fatigue strength evaluation will be also confronted with testimonials based on applications of standards.
\end{abstract}

\section{Introduction}

The bridge dilatation also referred as bridge closures are construction elements of the bridges which are primary used for thermal and humidity compensations. The lifetime and serviceability of the whole bridge can be extended by using such element as a part of such bridge structure. The lamella (scissors) types of those bridge closures are usually used for balancing higher dilatation displacements. If the structure is a relatively simple then during installation a bridge closures there is no necessity adjustment to be performed on a given bridge structure. Principle of the scissor mechanism is obvious and displayed in Fig.1.

The highest loading is transmitted by applied lamellas in the place of the upper aperture for pin as is shown in (Fig.1) for the first lamella. By passing the truck axle above the rail of such dilation closure, the effect is that this place is loaded with combination of the normal force and bending moment. Because the loading of this structure is a cyclically loading, in term of such dynamic character of that bridge operation, there is necessary to assess the bridge not only for expected static loading but also for the fatigue strength of considered structure. For correct assessment of the whole structure, it is very important to identify where it is the most critical point of the structure. For given structure of the bridge, the most critical point of whole structure was the weld of the rail console and stirrup see (Fig.1).

\footnotetext{
*Corresponding author: miroslav.sulko@stuba.sk
} 


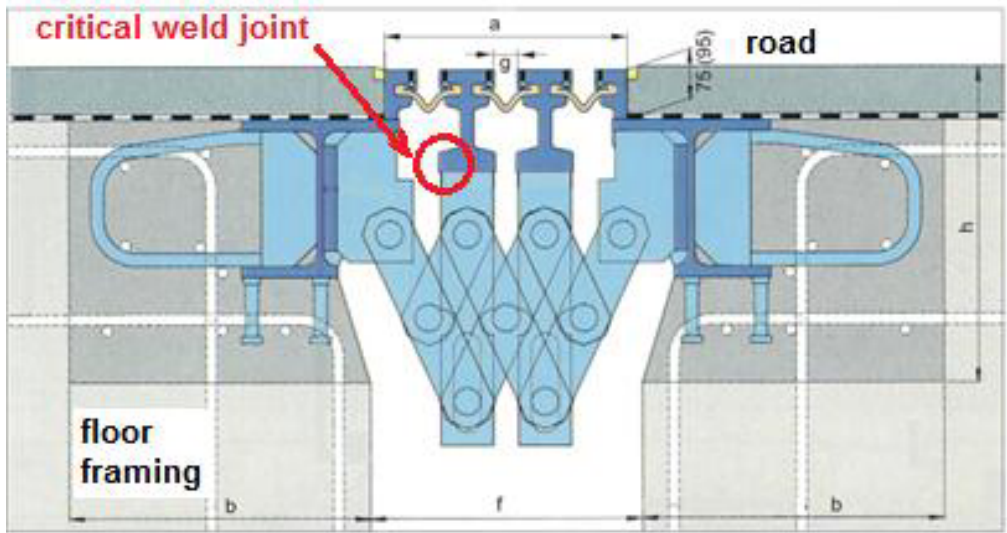

Fig. 1. Principle of usage the bridge closure with specified critical weld.

\section{Measuring of operational loading}

The assessment of the fatigue strength i.e., the resistance against the fatigue crack of steel structures, describes the standard of Eurocode3 (Design of steel structures - Part 2: Steel bridges), addition E, article. E.3.3 [1], where it is stated that the amplitude of normal stress can be evaluated by

$$
\Delta \sigma=\left(\phi_{h} \Delta \sigma_{h}+\phi_{v} \sigma_{v}\right) \gamma_{M f}
$$

where $\Delta \sigma$ is an overall amplitude of the normal stress,

$\Delta \sigma_{h}$ is an overall amplitude of the normal stress from horizontal loading (it is about $20 \%$ from vertical loading)

$\Delta \sigma_{v}$ is an overall amplitude of normal stress from vertical loading of the structure

$\phi_{h}=2.4$ or $\phi_{v}=2$ is a dynamic coefficient of the horizontal or vertical loading

$\gamma_{M f}=1.25$ is a safety coefficient

Vertical and horizontal stress amplitudes are designated for maximum prescribed loading of axels $130 \mathrm{kN}$ by Fig. 2.

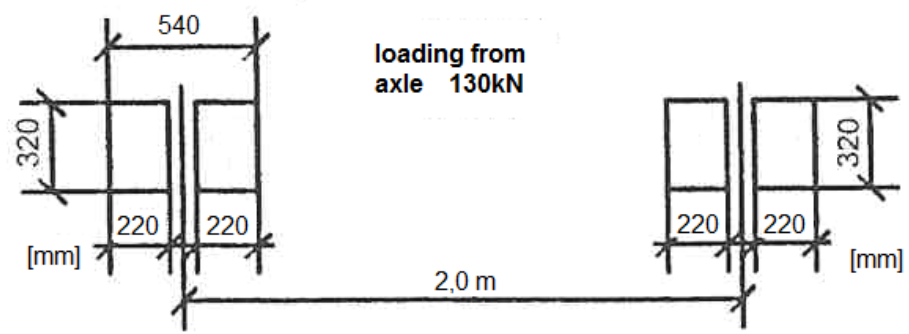

Fig. 2. Vertical loading during fatigue strength assessment.

For the first approximation, the required stresses by (Eq. 1) were obtained using mathematical model created for bridge dilatation MZ $240 \mathrm{~N}$ of the length $11.8 \mathrm{~m}$ where spacing between individual scissor mechanisms was about $1.4 \mathrm{~m}$ overhang of upper "I" beams $180 \times 83$ was $0.3 \mathrm{~m}$ (Fig. 3). 


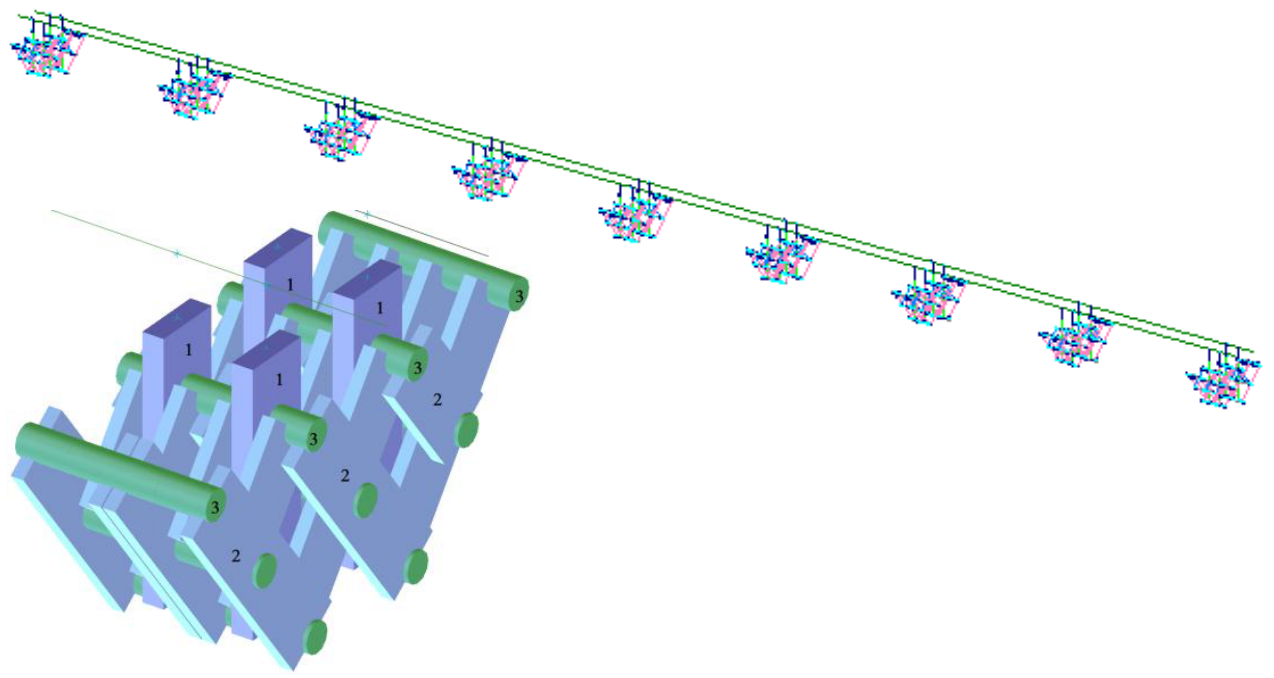

Fig. 3. Mathematical model of bridge dilation MZ240 N with main components: 1 - stirrup, 2 - lamella, 3 - pin.

The calculated values of stresses for the most disadvantageous position the axels transition in three under reviewing places for scissor mechanism are given in Table 1.

The high stress values, as well as requirements on lifetime test realization, led to developing abbreviated bridge dilation with two scissor mechanisms. In the lab, there was closure built-in concrete block and the loading was simulated as a half part of axle transitions with a pressure of $130 \mathrm{kN}$ (forced by crank mechanism). Pressure of the half part of an axle was simulated by two hydraulic cylinders. After all lab tests completion that represented about $1.10^{6}$ truck transitions were measured stress values of individual crosssections, the values are given in Table 1. Significant low stress values comparison with the results from mathematical model led to requirement of the direct measurement of stresses in the real bridge operation with implemented dilatation. The length of the dilatation MZ240 was $17 \mathrm{~m}$ and two main beams of the shape I $180 \times 83$ were supported by 12 scissor mechanisms deployed evenly about $1.4 \mathrm{~m}$. Throughout the dilations installation, there were also installed gauge sensors for sensing strains on the scissor mechanism number 3 a 4 as is shown in Fig. 4a.

The sensor deployment allowed evaluating of individual stress components in lamella (normal stress from vertical force and also from bending moment perpendicular to the direction of drive - Eq.2) and in a stirrup (normal stresses of vertical force and from bending moment in the direction of drive and perpendicularly to the drive direction - Eq.3) and possible shear stresses from torsion loading.

$$
\begin{gathered}
\sigma_{L}=\left|\sigma_{N}\right|+\left|\sigma_{M x}\right| \\
\sigma_{S}=\left|\sigma_{N}\right|+\left|\sigma_{M y}\right|+\left|\sigma_{M x}\right|
\end{gathered}
$$




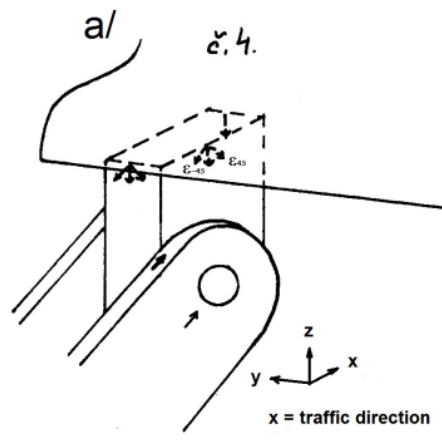

c.3.

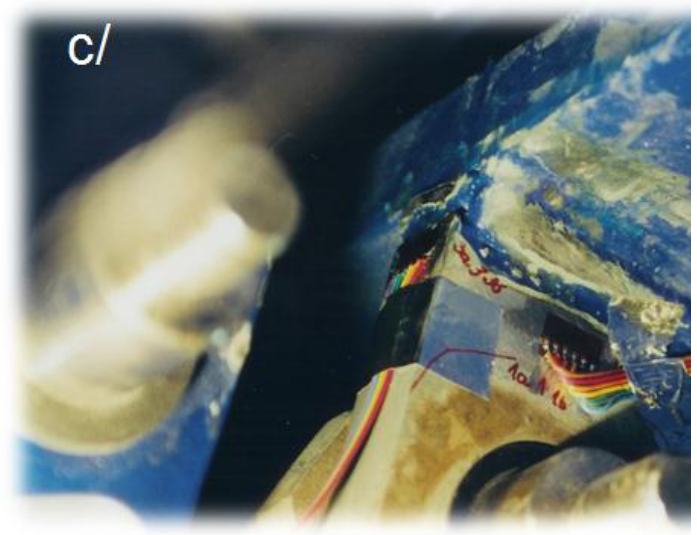

Fig. 4. Gauge sensors applied on bridge dilatation: a) scheme of deployment,

b) whole view on built-in dilation,

c) detail of sensors applied on stirrup of scissor 3 .

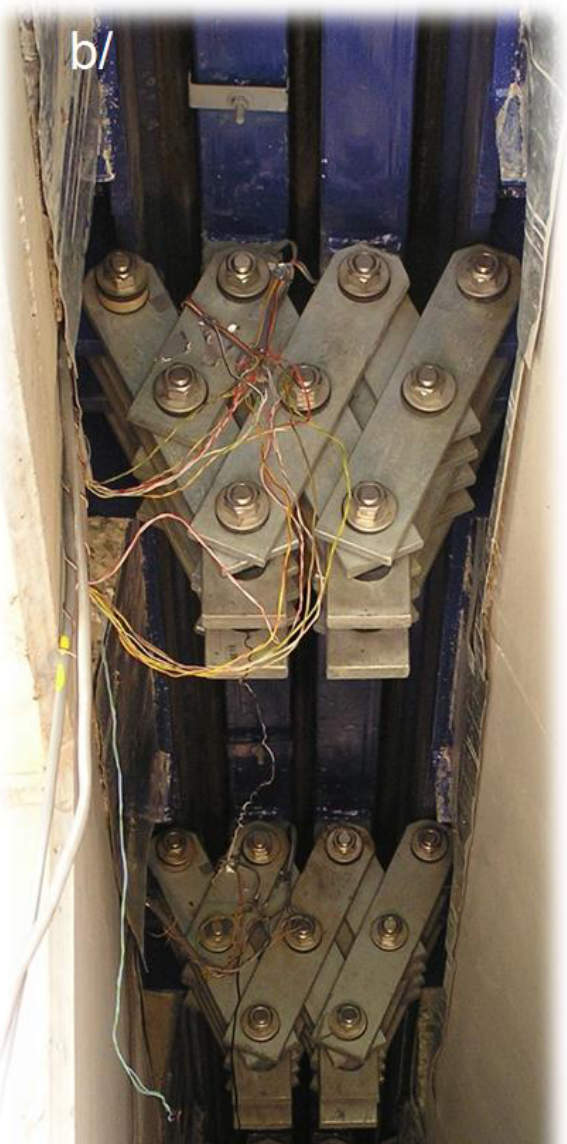

The gauge sensors were enclosed with protective mastic against moisture and mechanical damage throughout implementing into the bridge structure. The bridge dilatation was installed on bridge structure of the highway bypass near the city Uherské hradište (Czech Republic) next to support number 29 at the downward part of viaduct. The position of scissor mechanisms with installed sensors is shown in Fig. 5. 


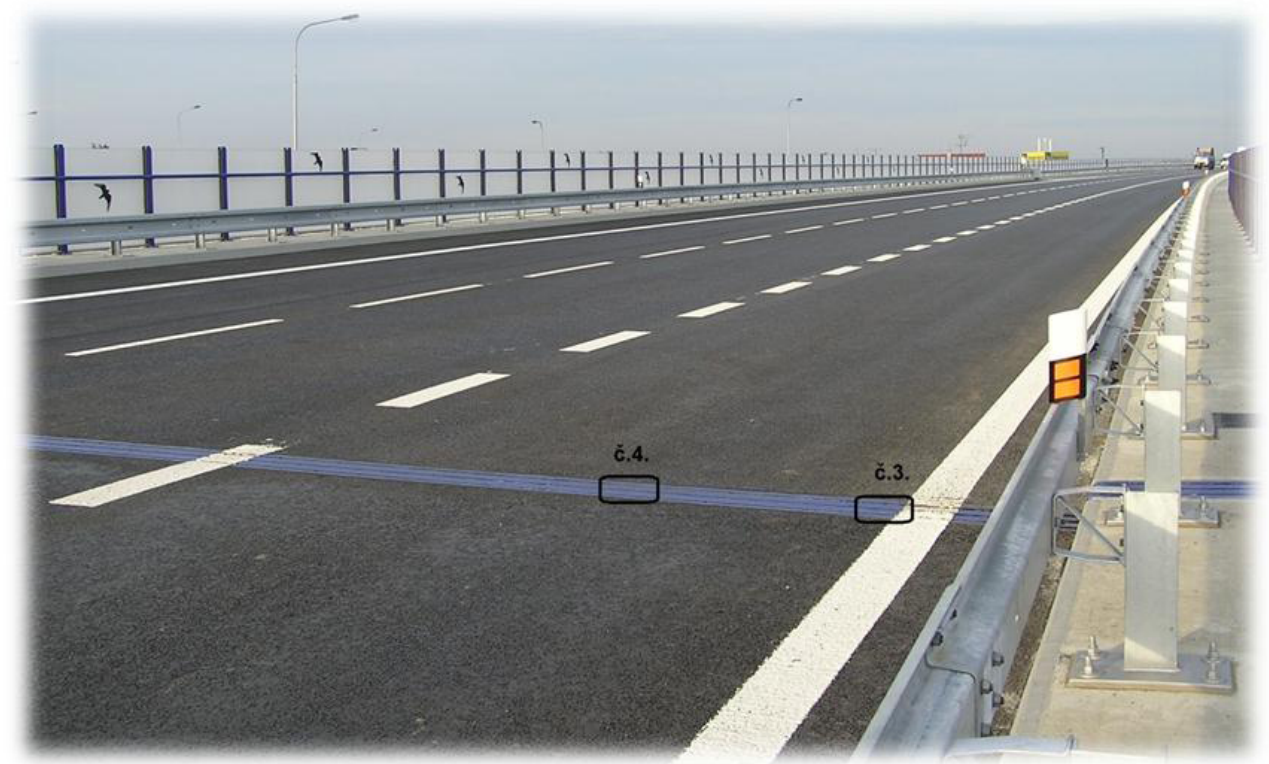

Fig. 5. The bridge dilation MZ240 N with installed gauge sensors throughout measurement.

The measurement was performed in the period with expected maximum traffic in Friday. Connection of measuring aperture and setting zero conditions was performed during night shift between 11.00 and 03.00 hour which this adjustment allowed without any problems. The measurement was conducted in time range from 3 a.m. to 2 p.m. Considering on the measured results was shown the continue of measuring is unsupported because the significant stress values form car transitions were registered only during transitions of trucks. During transitions of other vehicles were measured strains almost undetectable (they did not cause any measured loadings on closure).

The diagrams of stresses measured in places were evaluated using the expression of Mohr's circle and eq. 2 and 3. Sampling frequency was up to $500 \mathrm{~Hz}$ to precisely capture the peaks of stress during vehicle transitions. Processes of stresses of chosen time segments during observed period (total 11 hours) are displayed in Fig. 6. The displayed segments from the record of measured stresses represent range of stresses in critical place of weld Ibeam with stirrup on the scissor mechanism number 4 in length of $210 \mathrm{~s}$. The levels of stresses on the mechanism 3 were significantly lower. The peaks marker as K1 up to K5 are typical stresses for trucks transitions representing the lowest and highest stress levels. The different stress values are the reason of different truck weights (and loading of axels) and also different phasing of stiffness with instant time of transition through the bridge dilatation and different transition velocity. Throughout whole observed time range, values neither higher or lower, displayed in Fig. 6 were not recorded. Unwanted noise of equipment represents total amplitude of $2.5 \mathrm{MPa}$ which is acceptable precision of tensometric measuring devices. Small peaks relatively of huge number slightly overhung this level of noise represent transitions of cars which are by far more numerous as truck transitions.

The process of loading in the aperture of stirrup was considered identical with loading near the weld. The process of loading in lamella of the scissor mechanism number 4 in the place of aperture for pin displayed in the Fig. 7 are significantly lower as in the case displayed in Fig .6. 


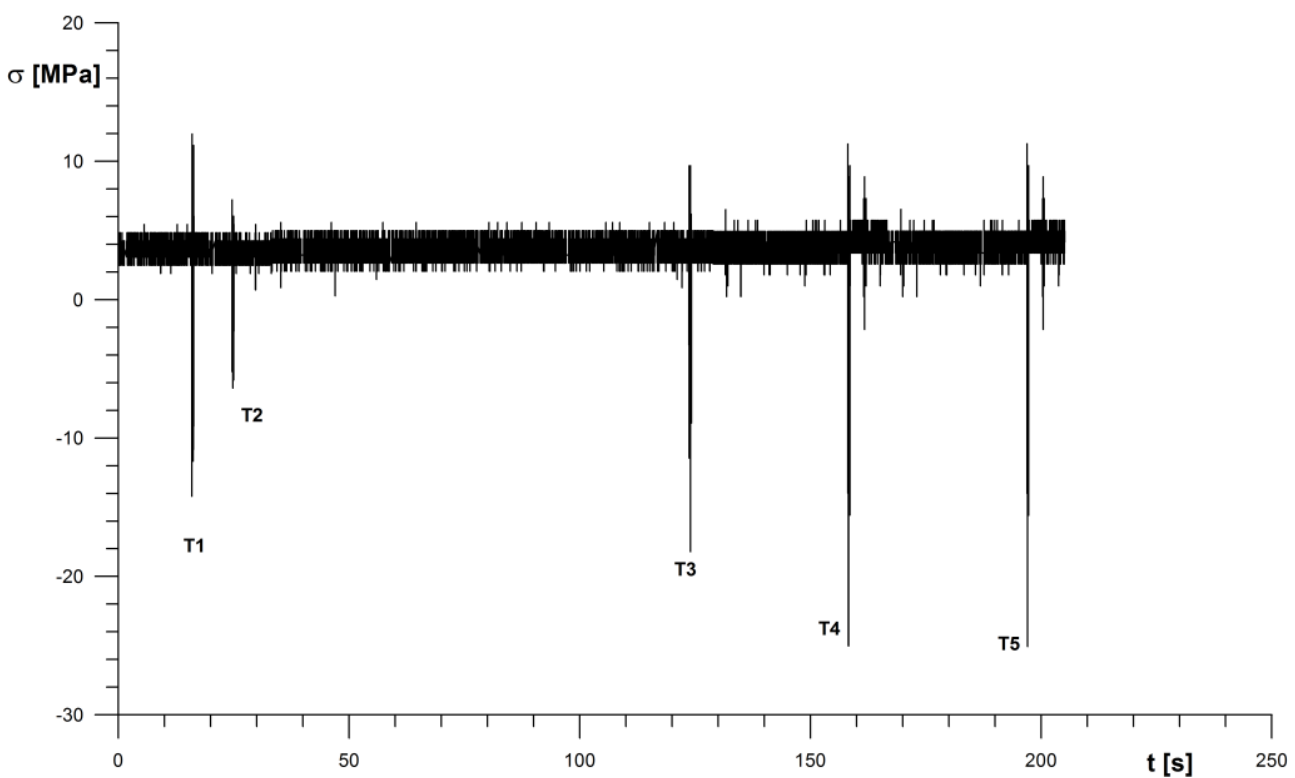

Fig. 6. Process of the stress for selected transitions of trucks (T1až T5) and cars.

\section{Fatigue strength assessment}

The measuring of loadings directly in operation at the critical part of the bridge dilation was the relevant basis for correct fatigue strength assessment. From the past operation and all gathered experiences, which were collected, was identified that the critical place of structure is the weld of the main I-beam and stirrup of the scissor mechanism. The weld resistance against the fatigue crack (fatigue strength) is possible to consider by various concepts [2-4]. In the term of legislative, the prescription [1] is valid, which for under reviewing the structure node establishes the maximum stress amplitude. On the other hand, in the term of the multiaxiality of a local stress-strain state, there is possible to use several kinds of approaches to assess that state [5,6]. For determining the corresponding stress amplitude, it is better to use approaches based on equivalent normal stress in the plane of maximum damage $[7,8]$.

The shear stresses in critical point were measured by pair of inclined gauge sensors $\varepsilon_{45}$, $\varepsilon-45$ in rosette (Fig. 4). Their values evaluated by the following term

$$
\tau=\left(\varepsilon_{45}-\varepsilon_{-45}\right) G
$$

have not exceeded the level of measuring sensitivity. The acquired results are equal with real loading of the bridge dilation where the shear stress might have been occurred only from inaccuracy of production and assembly. The equivalent amplitude is hence equal to amplitude of normal stress in the place of maximum fibre as it is shown in Fig. 6. Their values together with values obtained by mathematical model as well as allowance values of stress amplitudes for individual judged places are given in Table 1. 
Table 1. Calculated and measurement values of stresses.

\begin{tabular}{|c|c|c|c|c|}
\hline Place & $\begin{array}{c}\text { Normal stress } \\
\text { (Eq.1) model } \\
{[\mathrm{MPa}]}\end{array}$ & $\begin{array}{c}\text { Maximum } \\
\text { measured } \\
\text { amplitude } \\
{[\mathrm{MPa}]}\end{array}$ & $\begin{array}{c}\text { Maximum } \\
\text { allowable } \\
\text { amplitude [1, 4] } \\
{[\mathrm{MPa}]}\end{array}$ & Assessment \\
\hline $\begin{array}{c}\text { Stirrup 80×25 } \\
\text { weld }\end{array}$ & 93.9 & 26 & 36 & well \\
\hline $\begin{array}{c}\text { Stirrup aperture } \\
\text { for pin }\end{array}$ & 162.5 & 26 & 90 & well \\
\hline $\begin{array}{c}\text { Tie band } \\
\text { aperture for pin }\end{array}$ & 177.9 & 9 & 90 & well \\
\hline
\end{tabular}

\section{Conclusion}

In the contribution, there is presented the process of obtaining the relevant value of the stress which could allow the correct assessment of the fatigue strength in a critical point of the bridge closure. From three watched places like (the weld of main beam with the stirrup, aperture for pin in stirrup, aperture for pin in tie band) is the most critical point the weld of main beam with the stirrup. The amplitude stress determination using the mathematical model has not led to relevant results because it was difficult to catch the non-linear behaviour of plastic casings in combination with backlashes arisen during production and assembly. The direct measuring of stresses in critical points of dilatation were performed foremost at the miniaturized model and then directly in real operation of highway bypass of the city Uherské Hradište (Czech Republic). During measurements were sensed practically all types of transitions in the term of velocity transitions and loading of axels. The measurable values of stresses caused practically only the transitions of axel trucks (Fig. 6). The magnitudes of stresses in the most loaded fibre of the stirrup near the weld with main beam acquired significantly lower values like they were calculated by mathematical model given in Table 2. Based on the performed measurements, it is possible to conclude that the fatigue strength of the bridge dilatation is sufficient and it satisfies the appropriate prescriptions. This conclusion might be change in the case if the loading condition of the bridge structure are going to change significantly - e.g. by roadway deterioration and getting of the main beam at its surface. Unfortunately, such situation in operation of bridge dilatation could appear and it causes significant increase of the stress component in horizontal direction which even exceeds the value of the stress in vertical direction.

\section{References}

1. Eurocode 3. Design of steel structures. Part 1-9: Fatigue, UNI ENV 1993-1-9, 2005.

2. D.F. Socie, G.B. Marquis, Multiaxial Fatigue (SAE International, Warrendale, PA, 2000)

3. V. Chmelko, V. Kliman, M. Garan: Procedia Engineering 101, (2015)

4. V. Chmelko, Notch effects in operation of machines and structures (STU 2015)

5. J.A. Bannantine, D.F. Socie, ASTM STP 1122, Philadelphia, 249-275, (1992)

6. I.V. Papadopoulos, Int. Journal of Fatigue 23, (2001)

7. A. Carpinteri, A. Spagnoli, A.S. Vantadori, Fatigue of Engineering Materials and Structures 26, (2003)

8. M. Margetin, R. Ďurka, V. Chmelko, Frattura ed Integrita Strutturale 10, 37 (2016) 